\title{
La Micro y Pequeña Empresa en nuestros días
}

\author{
C.P.C. Zelma Wong Torres \\ C.P.C. Luisa E. Salcedo Guzmán
}

\section{RESUMEN}

Las Micro y Pequeñas empresas-MYPES, a nivel internacional y nacional, están consideradas como una unidad económica. En nuestro país representan el 98\% de la producción nacional; las Mypes pueden estar constituídas por una persona natural o jurídica, y tienen como finalidad el desarrollar actividades de extracción, transformación, producción y comercialización de bienes, así como la prestación de servicios.

A nivel internacional, no existe un criterio uniforme, en lo que se refiere al número de trabajadores para clasificar a una unidad productiva como microempresa, agrupándolas en una sola categoría.

Las MYPES son las principales protagonistas, para el surgimiento de la economía nacional. Es momento de dejar de lado la emisión de ordenamientos jurídicos que solo benefician a los que más tienen, olvidándose de crear aspectos legales para que los de bajos recursos puedan surgir. Es tiempo que las autoridades legislen para esa gran población, que continúa esperando, pero que se está cansando de esperar, incubándose una turbulencia social generada por el desaliento.

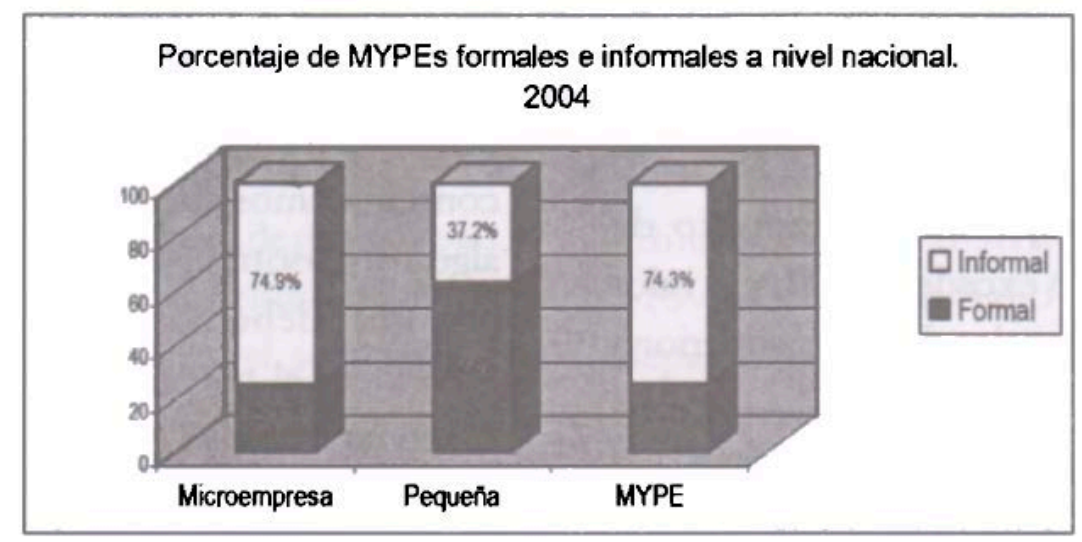

Fuente: SUNAT 2005, ENAHO 2002-INEI

Elaboración propia.

Las medianas y pequeñas empresas deben organizarse para poder progresar, pues la organización es uno Je los factores que determinará el éxito o el fracaso de las empresas. Es necesario socializar los beneficios je la economía de mercado, que en este momento es privilegio de unos cuantos.

El Estado ha dado un régimen especial que otorga -según se dice- beneficios a los microempresarios zara que puedan formalizar sus empresas hasta el año 2018, pero no corrige errores de leyes anteriores, 2 no modificarse montos de ventas, ni cantidad de trabajadores.

Palabras clave: Producción de servicios, micro y pequeña empresa, entidades públicas y privadas, sccialización económica. 


\section{INTRODUCCIÓN}

Es necesario establecer que las definiciones para la micro y pequeña empresa, varían en relación al nombre; internacionalmente, se conocen como pequeña y mediana empresa, es decir, PYME; también en el Perú se adoptaron dichas siglas, posteriormente se cambió la denominación como micro y pequeña empresa conocida hoy como MYPE.

En nuestro país, las empresas se clasifican de acuerdo al número de trabajadores y al monto de sus ventas en:

- Microempresa. Son empresas en las que los dueños son a la vez trabajadores. El número de sus trabajadores no excede de 10; y el nivel total de las ventas anuales no excede de 150 UIT*.

- Pequeña Empresa. El propietario de la empresa, no necesariamente trabaja en ella; el número de trabajadores no excede de 50 . El valor total de las ventas anuales fluctúa entre los 151 y 850 UIT.

- Mediana Empresa. El número de trabajadores no excede de 100; y el valor de las ventas anuales debe ser superior a las 850 UIT.

- Gran Empresa.El número de trabajadores es mayor de 101; y sus acciones se cotizan en la Bolsa de Valores.

El Banco del Trabajo creó el Premio Nacional a la Mujer Empresaria; evento que viene realizándose desde el año 2003 , en cuya oportunidad el premio fue de S/.1500; y en este año 2006 el premio equivale a S/. 6000.

Es de citar que en el año 2005, el segundo puesto de este premio fue otorgado a una empresaria ayacuchana, quien creó una Clínica de salud sexual, con precios al alcance de la población, el Banco de Traba ${ }^{2}$ tiene un trato especial con sus clientes microempresarios, premiando el cumplimiento oportuno de los pagos, con una disminución en los intereses.

En su primera convocatoria, el Banco solicitó el llenado de una ficha para conocer la historia de la empresa, en dicha ficha se consideraba: iniciativa, originalidad, esfuerzo, evolución del negocio y beneficio a la sociedad; posteriormente, se ha creado la «Fundación de la Gente», pues ya no será el Banco el encargado de entregar los premios, sino dicha organización, formada por peruanos.

Hay que reconocer y aprender de los buenos ejemplos que se ofrecen en el país, el carácter social y cultural que tiene en la familia la dinamización del proceso económico.

En nuestro país, no vamos a salir de donde estamos mientras esperemos o contemplemos que sean otros los que hagan algo por nosotros; tenemos que buscar lo que nos una; debemos tener la capacidad de reconocer el talento de otros y emularlos; como un ejemplo, podemos citar a Chile, el país vecino, donde se aprobaron 10 proyectos de ley y 5 medidas administrativas que están rigiendo desde el 23 de julio del 2003, y tienen como objetivo motivar el crecimiento de las pequeñas y medianas empresas, teniendo como pilares cuatro temas importantes: emprendimiento, competitividad y desarrollo tecnológico; mercado de capitales e institucionalidad del crecimiento; asimismo, se dio dos facilidades tributarias, se redujo en un $80 \%$ los intereses y las multas a quienes salden sus

Cada Unidad Impositiva Tributaria 2006 es equivalente aS $/ .3400 .00$ 
compromisos con el ente recaudador consiguiendo con este hecho que $300 \mathrm{mil}$ deudores paguen su deuda.

También tienen un Proyecto de Ley para el mercado de capitales, mediante el cual las empresas extranjeras en el país podrán emitir bonos en pesos chilenos, y la constitución de un Comité de mercado de capitales para diseños políticos de desarrollo de los mercados financieros, en Chile la pobreza extrema entre los años 1987 a 2003, era del $40 \%$; el día de hoy es el $18 \%$. Los chilenos importaron ideas y la plataforma para aplicarlas técnicamente, y difundieron a todos los niveles de la población el conocimiento sin egoísmos, sin mezquindades; los chilenos aplican sus actividades trazando metas bajas y las cumplen, están en gestiones para obtener la membresía plena en el Club de las Economías avanzadas y desarrolladas, OCDE.

\section{PERÚ}

Dadas las potencialidades de nuestro país, podemos remontar fácilmente a Chile, si abandonamos la cultura del secreto y el egoísmo mediocre que no permite un libre acceso al crecimiento, máximo provecho de los recursos humanos; no debemos ser destructores de ideas, sino creadores de ellas.

\section{PROBLEMAS DEL NO PODEMOS}

- No enseñar nuestros conocimientos a nuestros hermanos.

- No compartir la información con quien puede aprovecharla mejor que nosotros.

- No fomentar la creación de empresas.

- No enfrentar el miedo a la innovación,

- No aprovechar el potencial productivo.
Como resultado del NO PODEMOS: Estamos TRAICIONANDO A LA PATRIA, que se encuentra inmersa en un mundo globalizado, en donde es desigual la distribución de la riqueza.

\section{RESPONSABILIDAD SOCIAL Y AMBIENTAL}

Barrick Gold Corporation es una empresa minera aurífera, cuya sede está en Toronto, Canadá; es una entidad que está comprometida con el desarrollo del país, siendo la tercera productora de oro en el mundo, en 1996 adquirió la compañía Arequipa Resources, propietaria de Pierina, en Ancash; convirtiéndose en la segunda empresa minera más grande del Perú; invirtió $\mathrm{S} / .811$ millones de nuevos soles; para noviembre de 1998, Pierina comenzó con 7.2 millones de onzas de oro de producción.

En agosto, con una inversión de US \$ 340 millones de dólares, inició sus actividades en Lagunas Norte-Alto Chicama, en el distrito de Quiruvilca, provincia de Santiago de Chuco, en el departamento de la Libertad, su norte es:

- Competitividad: Con una reserva de 9100 millones de onzas de oro. 
- Filosofia:Compromiso con la protección del medio ambiente, desarrollo social de la comunidad, prácticas financieras transparentes.

- Tecnología: de punta (de última generación), respeto a las leyes y a la cultura peruana.

- Futuro: Colocó en la Bolsa de valores de Junín, bonos corporativos por 50 millones de dólares, las que fueron adquiridas por el fondo de pensiones e instituciones gubernamentales como COMIDE y FONDOS MUTUOS.

En el Alto Chicama, 350 profesionales realizaron estudios de impacto ambiental durante dos años frente a la temática biológica, fisica, socioeconómica, programa de manejo social y ambiental; incluyendo planos de explotación, cierre y postcierre; dicho estudio se realizó en Lagunas Norte, logrando la certificación ISO 14 001, en mérito a su política y prácticas ambientales.

Por concepto de canon minero, la Región Ancash obtiene de esta empresa el total de $\$ 100$ millones de dólares, que deben ser aplicados a tres temas: educación, salud y desarrollo de actividades productivas.

No hay que olvidar que el Perú ocupa el primer lugar en producción de oro en Sudamérica y el sexto a nivel mundial. Esta empresa ha mandado a construir un dique con la más alta tecnología, el mismo que podría soportar el mayor terremoto y la peor tormenta en 100 años.

Esa zona está progresando raudamente, debiendo el Estado ser el controlador de los compromisos con la empresa Barrick, que está poniendo en práctica su compromiso con la sociedad, brindando seguridad laboral a sus trabajadores, impulsando la educación y el progreso en las comunidades, así como la creación de talleres y participación en las comunidades más alejadas.

\section{CRECIMIENTO}

La oportunidad de transformación del país está en cada uno de nosotros. En los últimos 5 años, el Perú ha tenido el crecimiento más largo y sostenido de la historia; pero los indicadores de pobreza y el sentir de la mayoría de personas han desdibujado este hecho y la presentan como un país dormido. Pobres y ricos creando condiciones inmejorables para una turbulencia social que está incubándose.

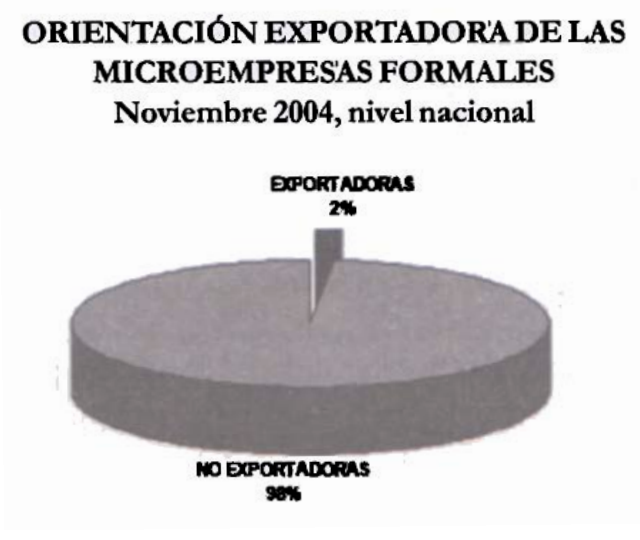

De los 17500 millones exportados, las Mypes solo han exportado 500 millones; sin embargo, la solución de las Mypes es llegar a la Capital de su Región o a Lima; debe expandirse el acceso de las Mypes a mercados más amplios, tanto internos como externos, reduciendo los costos y las trabas legales que le impiden crecer; debemos pensar en mercados más amplios como Estados Unidos, el cual es un mercado que debemos conquistar al igual que los páses europeos, asiáticos, centroamericanos y del sur. 
Debemos de plantear los derechos de propiedad con claridad y difundirlos, así como disminuir los costos de financiamiento, que son muy altos en nuestro país; debemos fijaruna adecuadaremuneración, mejor trato laboral y tributario para poder triunfar.

\section{CONCLUSIÓN}

\section{Apoyo estatal}

a. Difundir claramente el costo efectivo del crédito a las Mypes, sin gastos excesivos de publicidad, que distorsionan y confunden a la población. b. El Estado debe financiar los préstamos a interés cero a las Mypes, el no hacerlo es no mirar el futuro de las mismas.

c. Corregir los regímenes tributarios, que son tan onerosos.

d. Suprimir las consultorías, que solo contemplan aspectos políticos; poner en función los estudios realizados, y comprobar si se logran los objerivos para los cuales fueron contratados.

e. Es necesario que el Congreso apruebe leyes de calidad que mejoren $\mathrm{y} / \mathrm{o}$ cambien las ya existentes, en relación a las Mypes. 